\title{
THE ESTIMATION OF HEPATIC BLOOD FLOW IN MAN
}

\author{
By S. E. BRADLEY, F. J. INGELFINGER, G. P. BRADLEY, AND J. J. CURRY \\ (From the Evans Memorial, Massachusetts Memorial Hospitals, and the Department of Medicine, \\ Boston University School of Medicine, Boston, Massachusetts)
}

(Received for publication July 30,1945 )

A method of measuring hepatic blood flow is required in the quantitative analysis of hepatic function. Without this measurement, changes in hepatic function due to hemodynamic factors cannot be differentiated from those due to altered cellular activity, and metabolic exchanges cannot be accurately evaluated. Although various direct methods ( 1 to 7 ) have been devised and used in animals, the surgical manipulation necessary renders all such methods inapplicable to man. This paper describes a method based on the "Fick principle" by which hepatic blood flow has been estimated in man without trauma or anesthesia.

The "Fick principle" may be applied to any organ provided 3 facts are known: (1) the concentration of some substance, $\mathrm{X}$, in the blood entering the organ, (2) the concentration of $\mathrm{X}$ in the mixed venous blood leaving the organ, and (3) the total amount of $X$ removed from the blood by the organ each minute. Given these data, the blood flow through the organ per minute may be calculated by dividing the total removal rate of $\mathrm{X}$ by the amount of $\mathrm{X}$ removed from each milliliter of blood as it traverses the organ. In theory, this principle may be applied to the measurement of the blood flow through the human liver.

In practice, the concentration of $\mathrm{X}$ in the blood entering the liver cannot be determined unless $\mathrm{X}$ is a substance which may be assumed to exist in equal concentration in the afferent hepatic blood and in the peripheral venous or arterial blood. The concentration of $\mathrm{X}$ in the blood draining from the liver can be determined in hepatic venous blood obtained by an application of the venous catheterization technique (8). Since rapid and quantitative collection of bile is not feasible, the removal rate of $\mathrm{X}$ by the liver cannot be measured directly. An indirect method, however, is available if $\mathrm{X}$ can be given at such a rate that its blood level remains constant. Under these conditions, the infusion rate equals the hepatic removal rate, provided the extraction of $\mathrm{X}$ depends en- tirely upon hepatic activity. Bromsulphalein (BSP) was used as the test substance, $\mathrm{X}$, because it appeared to satisfy the above conditions.

\section{EXPERIMENTAL PROCEDURE}

After the subject 1 assumed the supine position on the fluoroscopic table, a catheter, 2 through which an isotonic saline infusion flowed, was inserted into the median basilic vein (8). Under fluoroscopic control, the catheter was passed into the superior vena cava and thence into the right atrium. The valve of the inferior vena cava could usually be avoided by directing the catheter tip to the right and posteriorly during its passage through the atrio-caval orifice. Once beyond this valve the tip was brought to bear more laterally and directed into the veins draining the right hepatic lobe. Catheterization of the left hepatic veins was somewhat more difficult. For the purposes of the present study, a right hepatic vein was catheterized on every occasion and the tip placed approximately in the center of the lobe. The catheter was kept in place for as long as 3 hours without untoward symptoms.

An intravenous infusion of isotonic saline containing BSP was next started in one of the lateral veins of the arm used for catheterization. A sample of the infusion was always taken for analysis. The rate of inflow, under the force of gravity, was controlled by a tunnel clamp (made by the Harvard Instrument Company) at $4 \mathrm{ml}$. per minute, measured with a calibrated Murphy drip (15 drops per $\mathrm{ml}$.). By this device the inflow rate could be maintained remarkably constant, although it varied occasionally as much as $0.06 \mathrm{ml}$. per minute. The BSP concentration of the infusion was usually adjusted so that approximately $3.0 \mathrm{mgm}$. were delivered per minute per

1 The 23 subjects examined in this study were drawn for the most part from a youthful group under penicillin therapy for primary or secondary syphilis. Except for syphilis, they appeared to be in good health and, as far as could be judged clinically, had no evidence of hepatic disease. All had had sufficient therapy to induce healing of lesions involving the skin or mucous membranes. The subjects were examined in the resting state and were either fasting or at least 3 hours post-prandial.

2 The catheters used in this study were designed and manufactured for use in this and other studies by the United States Catheter and Instrument Corporation, Glenn Falls, New York. They are $100 \mathrm{~cm}$. in length and terminate in a slightly-curved whistle tip ("Cournand Tip") with 1 "eye." 
TABLE I

Estimated hepatic blood flow in man

(All data in this table were obtained under standard conditions in resting subjects at least 3 hours post-prandial. Only studies in which the serum level of bromsulphalein was constant or changing no more than $0.0005 \mathrm{mgm}$. per ml. per minute are presented.)

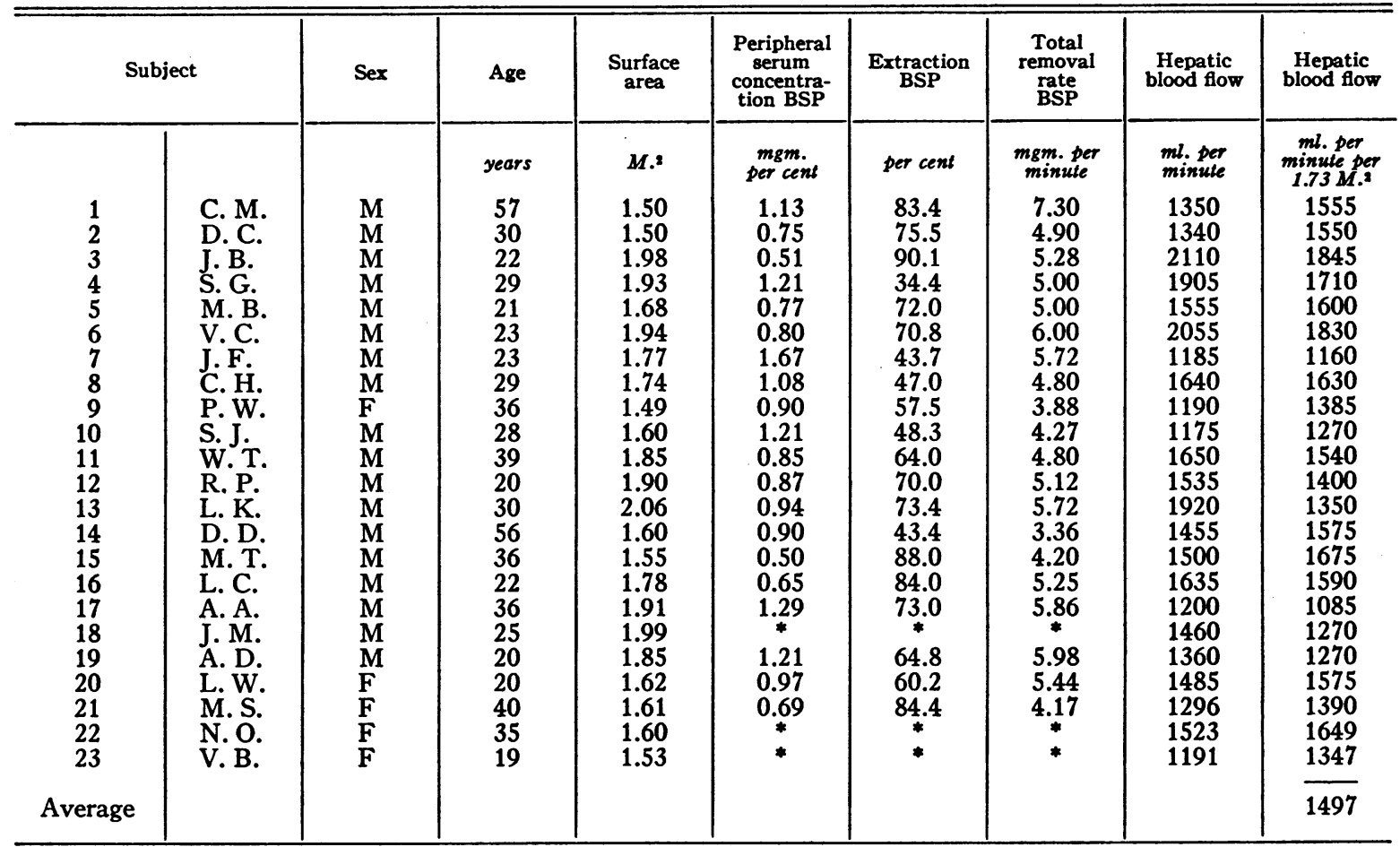

* In these studies hepatic blood was obtained at various sampling sites. The figures for EHBF are averages of 3 or more values. See Table II for details.

square meter of body surface. Faster rates of delivery often resulted in a rising BSP serum level. A priming dose of BSP (150 mgm.) was given to 15 subjects (J. F. to M. S., Table I) to raise the serum level quickly to about $1 \mathrm{mgm}$. per cent and to shorten the time of equilibration.

Samples of blood were obtained, as a rule, at 10-minute intervals over a period of an hour or more. After the salt solution in the venous catheter was washed out by withdrawing several $\mathrm{ml}$. of blood, 8 to 15 additional $\mathrm{ml}$. were collected in a clean, dry, sterile syringe. Simultaneously, a sample of blood was withdrawn from the vein or artery of the opposite arm.

The BSP concentration in the serum was determined colorimetrically. One or $2 \mathrm{ml}$. of serum was pipetted into an Evelyn colorimeter tube and the volume made up to 10 $\mathrm{ml}$. with isotonic sodium chloride solution. If the concentration of BSP in the serum was estimated at less than $1.5 \mathrm{mgm}$. per $100 \mathrm{ml}$., $2 \mathrm{ml}$. of serum was used; if more than $1.5 \mathrm{mgm}$. per cent, $1 \mathrm{ml}$. sufficed. With concentrations over $4 \mathrm{mgm}$. per $100 \mathrm{ml}$., $1 \mathrm{ml}$. serum was made up to $20 \mathrm{ml}$. in order to obtain good readings. The diluted serum was analyzed in the macro-unit of an Evelyn photoelectric colorimeter with a $\mathbf{5 8 0}$ filter. After a "central setting" was obtained, 2 drops of concentrated
$\mathrm{NaOH}$ were added, the mixture well agitated, and a reading taken within 1 minute of adding the alkali. The BSP concentration was obtained from the galvanometer reading by using a calibration curve, and by correction for the dilution. All determinations were made in duplicate. ${ }^{3}$

${ }^{3}$ A complete evaluation of the method is to appear elsewhere, but the following points are of importance:

(1) For calibration, weighed samples of pure bromsulphonphthalein powder ( $\mathrm{H}$. W. and D.), dissolved in 0.85 per cent sodium chloride solution, were diluted to concentrations ranging between 0.05 and $0.8 \mathrm{mgm}$. per $100 \mathrm{ml}$. Galvanometer readings were made as described above, and the results plotted on semi-logarithmic paper against the known concentrations. A straight line relationship was obtained up to a concentration of $0.4 \mathrm{mgm}$. per $100 \mathrm{ml}$; ; beyond this point, the line showed a moderate tendency to flatten out. For this reason, all the samples were diluted to bring the concentration of BSP below $0.4 \mathrm{mgm}$. per $100 \mathrm{ml}$.

(2) The addition of concentrated $\mathrm{NaOH}$ to diluted serum not containing BSP reduced the "central setting." This decrease was minimal if the serum was clear and pale, but was pronounced if gross hemolysis or turbidity were present. Consequently, samples which were grossly 


\section{Calculation of hepatic blood flow}

Figure 1 sets forth diagrammatically the procedure followed in estimating hepatic blood flow. Peripheral and hepatic serum concentrations of BSP were plotted on semi-logarithmic paper against time. Straight lines were drawn between these points $(\mathrm{P}$-peripheral venous concentration of BSP and $\mathrm{H}$-hepatic venous concentration, Figure 1). Values of $\mathrm{P}$ and $\mathrm{H}$ used in the calculation of hepatic blood flow were then obtained by interpolation from the curves at a time midway between measured values of $P$ (cross-marks connected by interrupted line on $\mathrm{P}$ and $\mathrm{H}$ curves, Figure 1). With constant peripheral plasma levels (Figure 1), the total BSP removal rate, $R$, was taken as equal to the rate of infusion in mgm. per minute. Then taking EHBF as the estimated hepatic blood flow, $P$ as the concentration of BSP in mgm. per $100 \mathrm{ml}$. in the afferent hepatic blood, and $\mathrm{H}$ as the concentration in the efferent hepatic blood:

$$
\mathrm{EHBF}=\frac{\mathrm{R}}{0.01(\mathrm{P}-\mathrm{H})} \times \frac{1}{1-\text { hematocrit }}
$$

Hepatic blood flow may also be estimated if the levels of BSP in the peripheral blood are changing, but this

hemolyzed or turbid were discarded. In other samples, the effect of alkali on the serum presumably introduced a small error which lowered the BSP readings below their actual value.

Known quantities of BSP, when added to pale, clear sera, were recovered with less than a 5 per cent error. In more turbid or pigmented sera, recovery of strong BSP solutions was similarly satisfactory ; but from weaker solutions (i.e., 0.2 to $1.0 \mathrm{mgm}$. BSP per $100 \mathrm{ml}$.) recovery was only 85 to 95 per cent. In the range of BSP concentration used in the study of hepatic blood flow, the absolute error was never more than $0.1 \mathrm{mgm}$. per $100 \mathrm{ml}$. Since this error probably affected hepatic and peripheral venous blood similarly, the calculations of estimated hepatic blood flow were not significantly influenced.

(3) Samples of serum containing BSP in its colorless state could be kept in the ice box for 4 days without apparent loss of dye. Once alkali had been added, however, whether to diluted or undiluted serum, the color thus developed diminished in intensity very slowly.

(4) BSP was not contained in washed red cells. Serum proved easier to use than plasma. Although BSP in saline solutions dialyzed freely across a cellophane membrane, no dialysis occurred if BSP was dissolved in serum. BSP in serum thus appeared to be completely bound by protein. According to salting-out experiments, this linkage seemed to be preponderantly with the albumin fraction. No method of precipitating proteins (by acetone, salting-out, etc.) that does not decrease the quantity of recoverable BSP has been found.

(5) If the concentration of BSP in the undiluted serum was over $0.5 \mathrm{mgm}$. per $100 \mathrm{ml}$., duplicate readings checked within 5 per cent. With serum concentrations over 1.0 mgm. per $100 \mathrm{ml}$., duplicate readings checked within 3 per cent and usually yielded identical results. estimate requires the measurement of plasma volume. When serum levels are rising, it is obvious that less dye is removed than is administered. Hence, the removal rate is equal to the rate of administration less the rate of retention. Taking I as the rate of infusion of BSP in $\mathrm{mgm}$. per minute, $R$ as the total removal rate of BSP in mgm. per minute, $\mathrm{V}$ as the total plasma volume in $\mathrm{ml}$., and $\Delta \mathrm{P}$ as the rate of change in the concentration of the dye in the peripheral serum in $\mathrm{mgm}$. per $\mathrm{ml}$. per minute,

$$
\mathrm{R}=\mathrm{I}-(\Delta \mathrm{P} \times \mathrm{V})
$$

when the blood level is rising (Figure 1). When the peripheral level is falling (Figure 1):

$$
\mathrm{R}=\mathrm{I}+(\Delta \mathrm{P} \times \mathrm{PV})
$$

The change in the peripheral serum level (mgm. per ml.) during the minute immediately preceding the midpoint was taken as $\Delta \mathbf{P}$. Thus the difference between the concentrations per $\mathrm{ml}$. at the two cross-marks on curve $\mathbf{P}$ (Figure 1) is equal to $\Delta \mathrm{P}$. Plasma volume (V) was estimated from the tables of two other investigators (9). This procedure may introduce a small error that depends upon the deviation of the subject from the average.

In this report, hepatic blood flow was calculated only from data obtained when the level of BSP in the peripheral blood was constant or changing less than $0.0005 \mathrm{mgm}$. per $\mathrm{ml}$. per minute. Two studies have been excluded from the results because hemolysis and very low plasma levels of BSP caused analytical difficulties.

\section{Validity of the method}

The validity of the method hinges upon 4 basic assumptions; viz., (1) bromsulphalein is removed from the blood exclusively by the liver, (2) the concentration of the dye in the peripheral venous blood corresponds to the concentration in the blood entering the liver, (3) the BSP level in a sample of blood taken from a right hepatic vein is representative of the level in total pooled hepatic venous output, and (4) the basal hepatic blood flow is not altered by BSP in the blood nor by the catheter in the liver.

Although its seems generally agreed that bromsulphalein is removed from the blood chiefly by the liver, the location of intrahepatic and extrahepatic uptake sites remains disputed. Certain investigators favor the view that BSP is taken up by the reticulo-endothelial system both within and without the liver because removal of the dye is retarded when cells of this system are blocked by India Ink or removed by splenectomy $(10,11)$. The method of determining hepatic removal rate used in this study is not materially affected, however, whether BSP is removed entirely by the 


\section{calculation of estimated hepatic blOOD flOW}
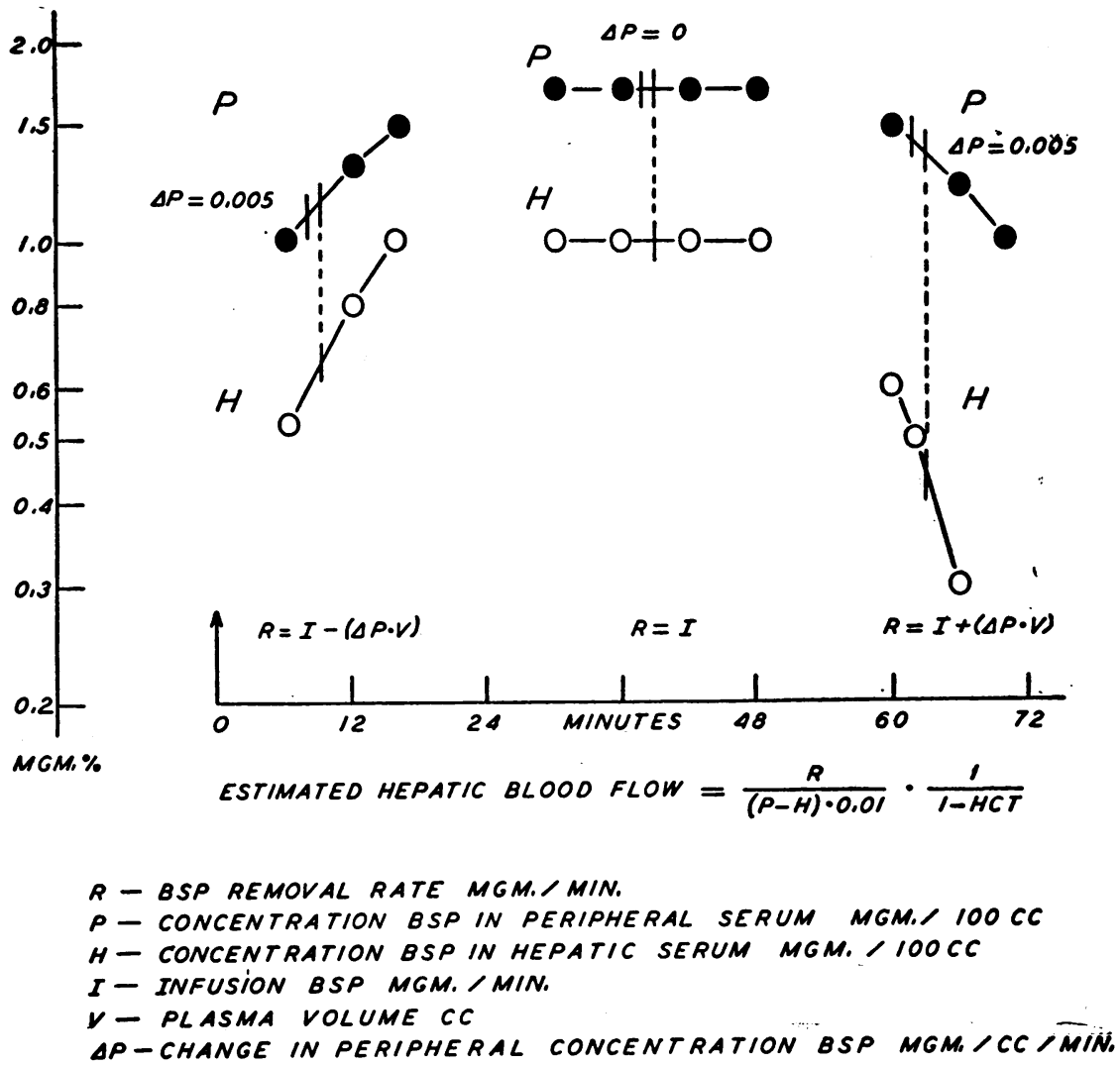

FIG. 1

Serum concentrations (mgm. per $100 \mathrm{ml}$.) of BSP in peripheral venous blood (P) and in hepatic venous blood $(\mathrm{H})$ are plotted on semi-logarithmic paper against time. Concentrations used in the calculation of EHBF are obtained by interpolation at the midpoint between measured concentrations on $\mathrm{P}$ (right-hand cross-mark of each pair on $\mathrm{P}$ ), and at the same time on $\mathrm{H}$ (cross-mark on $\mathrm{H}$ ). The difference between these 2 values $(\mathrm{P}-\mathrm{H})$ multiplied by 0.01 yields the amount of BSP removed from each $\mathrm{ml}$. of serum as it passes through the liver. Each $\Delta \mathrm{P}$ was taken as the difference between BSP concentrations per $\mathrm{ml}$. of serum at the midpoint and 1 minute prior to the midpoint on $\mathrm{P}$ (cross-marks on $\dot{\mathrm{P}}$ ).

liver or partially by reticulo-endothelial cells elsewhere in the body.

The extrahepatic portions of the reticulo-endothelial system by which. BSP could be withdrawn from the blood lie principally in the portal circulation and in the bone marrow. Since the blood draining from the portal vein, except for a small volume lost through collateral channels, is emptied into the inferior vena cava by way of the hepatic veins, the portal circuit is, in effect, an extension of the hepatic vascular bed. Hence, removal of the dye by the spleen or gastrointestinal tract is equivalent to removal by the liver.4 A significant removal of dye by the bone marrow would result in an erroneously high estimate of hepatic removal rate and of hepatic blood flow. There is

4 The truth of this statement may be demonstrated as follows :

(1) Assume that the actual hepatic blood flow is 1,500 ml. per minute. This figure will be given by the formula if (a) the liver alone is removing BSP from the blood; (b) the BSP concentration in the peripheral blood is maintained at $1.4 \mathrm{mgm}$. per $100 \mathrm{ml}$. of serum; (c) the concentration of BSP in serum leaving the liver is 0.6 mgm. per $100 \mathrm{ml}$. (i.e., $\mathrm{P}-\mathrm{H}=0.8 \mathrm{mgm}$. per $100 \mathrm{ml}$.); 
good reason to believe that this possibility is unlikely. In the first place, the volume of blood flowing to the bone marrow probably is small and the amount of BSP available for removal by this route, therefore, should be minimal. Furthermore, as long as the serum concentration of BSP remains unchanged, the reticulo-endothelial cells of the bone marrow presumably become saturated with respect to that concentration and remove no further dye.

Removal by the kidney is very small in normal subjects, amounting to no more than $12 \mathrm{mgm}$. per hour when the blood level is maintained at $1 \mathrm{mgm}$. per $100 \mathrm{ml}$., but losses by this route may be large if proteinuria is present (12). The dye is completely bound to the plasma proteins and does not dialyze from plasma through cellophane membranes. It is unlikely, therefore, that significant amounts of the dye are lost from the blood stream by diffusion into extravascular water. Moreover, it has not been found in ascitic fluid even when present in the blood in high concentration (12). A small amount of BSP may be destroyed in the body, but this activity is probably negligible.

Finally, no evidence of significant removal of the dye elsewhere in the body has been obtained in these studies. Concentration of BSP in blood

(d) the rate of infusion is $6 \mathrm{mgm}$. per minute; and (e) the hematocrit is 50 per cent. Then:

$$
\mathrm{EHBF}=\frac{6}{0.01 \times 0.8} \times \frac{1}{0.5}=1,500 \mathrm{ml} \text {. per minute }
$$

(2) Assume, on the other hand, that splenic activity accounts for $1.2 \mathrm{mgm}$. per minute of the total removal rate, and that $300 \mathrm{ml}$. of blood (150 ml. serum) passes through the spleen per minute. If the splenic venous return drained directly into the peripheral venous system, the calculations would yield a falsely high hepatic blood flow, for the total removal rate would remain at $6 \mathrm{mgm}$. per minute, while the peripheral-hepatic venous concentration difference, deprived of its splenic component, would be reduced. The spleen, however, drains through the liver. Hence under the conditions assumed above, 1,500 ml. of blood reaching the liver per minute through the portal vein would contain $600 \mathrm{ml}$. of serum with a BSP concentration of $1.4 \mathrm{mgm}$. per $100 \mathrm{ml}$. and $150 \mathrm{ml}$. serum coming from the spleen containing $0.6 \mathrm{mgm}$. BSP per $100 \mathrm{ml}$. The P-H difference due solely to hepatic activity would then equal $0.64 \mathrm{mgm}$. per cent and :

$$
\mathrm{EHBF}=\frac{4.8}{0.01 \times 0.64} \times \frac{1}{0.5}=1,500 \mathrm{ml} . \text { per minute }
$$

the same figure derived under assumption (1).

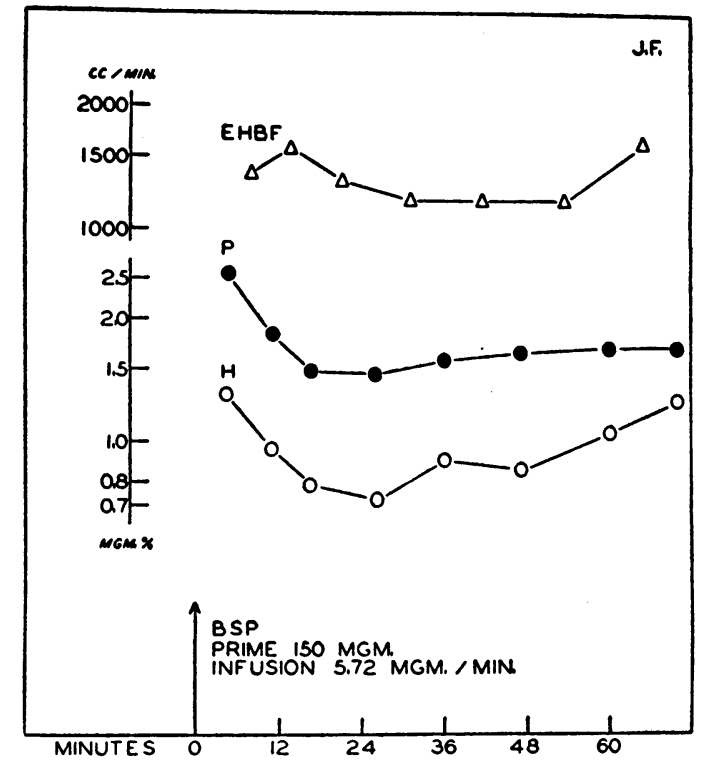

Fig. 2. Illustrative Study of Estimated Hepatic Blood Flow in MaN

Subject J. F., a 23-year-old, white male, had completed a course of penicillin therapy for primary syphilis. Concentrations of bromsulphalein in the peripheral venous serum ( $P$ ) following intravenous administration of the dye at the arrow are plotted as closed circles. The concentrations of BSP in hepatic venous serum $(H)$ are plotted as open circles. The estimated hepatic blood flows (EHBF) are plotted as open triangles. EHBF does not change greatly over a period of more than 1 hour.

taken simultaneously from an antecubital vein, the brachial artery and the inferior vena cava has been found to differ by no more than 5 per cent.

In summary, then, it appears that the amount of bromsulphalein lost by destruction, by diffusion, by extraction in the bone marrow, and by way of the urine is not large enough to invalidate the first assumption; i.e., the removal of BSP can be considered equal to the infusion rate when the level of dye in the peripheral blood remains constant.

Since the concentration of BSP in peripheral arterial and venous blood exhibits no significant difference, blood taken from an antecubital vein should contain the same proportion of dye as arterial blood entering the portal system and the liver. Although portal organs other than the liver may remove BSP, it has been shown that the inclusion of portal blood in hepatic venous outflow cancels any error introduced in this manner. For 
these reasons, the concentration of BSP in a peripheral vein has been considered equivalent to the dye content of blood entering the liver.

Mixed hepatic venous blood cannot be obtained in man because the hepatic veins empty separately into the inferior vena cava. However, blood draining from a large portion of the liver may be sampled. In this study, blood has been taken from one of the right hepatic veins. Obviously, data obtained from such localized sampling is not satisfactory for calculating the true blood flow of the whole liver. The results presented in Table I, therefore, have been designated "estimated hepatic blood flow" (EHBF).

To what extent EHBF may deviate from true blood flow cannot be ascertained without a means of sampling total pooled hepatic venous blood. The magnitude of deviation may be judged, however, by comparing BSP extraction at different locations in the same liver. ${ }^{5}$ Table II sets forth the data obtained in 3 such studies. The observed variation in BSP extraction may be explained in part by reflux of blood from the inferior vena cava since extraction appeared to decrease in several instances as the caval orifice was approached. This source of error may be avoided by placing the catheter tip several centimeters beyond the orifice and by withdrawing blood only when the subject is breathing quietly. A more fundamental cause of the unequal BSP extractions may be the fact that different areas in the liver contain varying proportions of capsular, portal, and other non-extracting tissue.

5 Extraction of BSP by the liver may be expressed as the percentage of dye removed from each $\mathrm{ml}$. of blood as it passes through the liver; i.e., the difference between BSP serum concentrations in the peripheral and hepatic venous blood divided by the serum concentration in the peripheral blood.

TABLE II

Bromsulphalein extraction and EHBF at various hepatic sampling sites. The symbols mark the position of the catheter tip in the liver during sampling

\begin{tabular}{|c|c|c|c|c|c|c|c|}
\hline Subject & Position of catheter in liver & \multirow{2}{*}{$\begin{array}{c}\begin{array}{c}\text { BSP } \\
\text { peripheral } \\
\text { serum }\end{array} \\
\text { mgm. per } \\
100 \mathrm{ml} .\end{array}$} & \multirow{2}{*}{$\frac{\begin{array}{c}\text { Extraction } \\
\text { BSP }\end{array}}{\text { per cent }}$} & \multirow{2}{*}{$\begin{array}{c}\frac{\begin{array}{c}\text { BSP total } \\
\text { removal } \\
\text { rate }\end{array}}{\underbrace{\text { minute }}_{\text {mgm. per }}} \\
\end{array}$} & \multicolumn{2}{|c|}{ Estimated hepatic blood flow } & \multirow{3}{*}{ 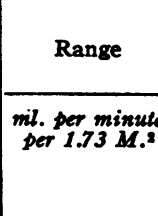 } \\
\hline \multirow{4}{*}{ J. M. } & & & & & $\begin{array}{l}\text { ml. per } \\
\text { minute }\end{array}$ & \begin{tabular}{|l} 
ml. per minute \\
per $1.73 \mathrm{M.}$
\end{tabular} & \\
\hline & r & 1.20 & 86.2 & 6.17 & 1088 & 945 & \\
\hline & C & 1.03 & 74.6 & 6.00 & 1423 & 1238 & \\
\hline & & 0.91 & 66.2 & 6.17 & 1860 & 1618 & 673 \\
\hline \multirow{4}{*}{ N. 0.} & & 1.24 & 49.4 & 4.64 & 1286 & 1390 & \\
\hline & & 1.23 & 39.4 & 4.82 & 1696 & 1832 & \\
\hline & & 1.08 & 49.1 & 4.75 & 1530 & 1655 & 442 \\
\hline & & 1.07 & 47.4 & 4.75 & 1590 & 1718 & \\
\hline \multirow{4}{*}{ V. B. } & & 1.50 & 43.0 & 4.85 & 1368 & 1546 & \\
\hline & & 1.48 & 46.0 & 4.92 & 1315 & 1486 & \\
\hline & & 1.41 & 55.6 & 4.92 & 1140 & 1290 & \\
\hline & & 1.37 & 69.1 & 4.92 & 941 & 1065 & 481 \\
\hline
\end{tabular}


For any individual liver, the figure for true blood flow probably falls somewhere within the range of EHBF calculated at different sampling sites, and the range thus permits an estimate of the experimental error. In 3 subjects, this range was 442,481 , and $673 \mathrm{ml}$. per minute respectively (Table II). In other studies in which the position of the catheter was less rigidly controlled, the range of blood flow in any 1 subject never exceeded $800 \mathrm{ml}$. per minute. Hence, any observed EHBF may be said to approach true blood flow within the limits of this range. It is of interest that the range of $\mathrm{EHBF}$ as recorded in a group of individuals (Table I) also falls within $800 \mathrm{ml}$. per minute.

Certain dyes may affect hepatic blood flow (13). The effect of BSP in this respect has not been determined, but no relationship was noted in this study between EHBF and the serum concentration, total dose, or the rate of infusion of BSP. However, the possibility of an immediate maximal response of the hepatic vasculature to minimal amounts of BSP cannot be eliminated.

Passage of the catheter through the peripheral veins often induced a venous spasm which usually was fleeting, but at times was strong enough to impede catheterization. A similar reaction apparently occurred in the liver in some instances when the catheter was placed in the smaller radicles of the hepatic vein. On these occasions, the subject complained of epigastric pain which was immediately relieved by withdrawal of the catheter. A definite sense of resistance, possibly due to spasm of the vein, was noted by the operator during the withdrawal. As a rule, however, the catheter was passed without difficulty into many hepatic venous radicles and deep into the substance of the liver without evidence of spasm. Since hepatic venospasm occurred infrequently and was always transient, it is unlikely that the figures presented in Table I were affected in any way by such a reaction.

\section{COMMENT}

Study of the circulation of blood through the lobular sinusoids by means of the quartz rod illumination technique revealed an intermittent and irregular rhythmicity of the intrahepatic blood flow of anesthetized animals (14). If such an irregular intermittency of hepatic blood flow were characteristic of relatively large sections of the human liver, BSP extraction might be expected to fluctuate widely from moment to moment. It was demonstrated repeatedly, however, that the percentage of BSP extracted from the blood obtained at a single sampling site in the liver remained constant for periods of 1 hour or more. If intermittency occurs in man, it must occur in very small vascular units alternating in a purely random manner.

The constancy of BSP extraction also indicates the absence of shunting activity in the human liver under the conditions of this study. The low extraction percentage (less than 60 per cent) found in 7 subjects may have been caused, it is true, by sustained shunts. However, no direct anastomoses between the portal and hepatic venous circuits have been demonstrated anatomically in man (15), and it is possible that the low extraction percentages in these instances arose from saturation of hepatic BSP removal mechanisms.

Since it appeared that 75 per cent of the intrahepatic circulation in animals was inactive at any moment, a "reserve" permitting 4-fold expansion of hepatic circulation and function has been postulated (14). In accord with this hypothesis, a direct method (7) of measuring hepatic blood flow in the dog has yielded a range of 40 to $160 \mathrm{ml}$. per 100 grams of liver tissue, with an average of 100 $\mathrm{ml}$. per 100 grams. The average figure for $\mathrm{EHBF}$ in ideal man (surface area-1.73 M. ${ }^{2}$ ) was 1,497 $\mathrm{ml}$. per minute or (assuming average normal liver weight) $100 \mathrm{ml}$. per 100 grams of tissue, a figure in complete agreement with that found in the dog. This finding gives weight to the view that average EHBF approximates the average true hepatic flow. The limited area of variation (1,085 to $1,845 \mathrm{ml}$.), however, stands in marked contrast to data derived from animal study. It is possible that the wide range observed in the dog is attributable to the trauma and anesthesia necessary in most methods used. On the other hand, man may not be capable of such a wide variation at rest because of the absence of a "reserve" apparently present in some animals.

\section{SUMMARY}

1. The hepatic blood flow in man has been estimated by the following procedure: 
a. By means of a constant intravenous infusion, Bromsulphalein was given at such a rate that the concentration of the dye in the peripheral blood remained unchanged. Under these conditions, the rate of BSP removal by the liver was assumed to equal the infusion rate. This assumption appears to be valid, even if BSP is removed in the portal circulation by reticulo-endothelial cells outside the liver. Any activity of reticulo-endothelial cells in other extrahepatic depots presumably ceases when an equilibrium is reached between serum and cellular concentrations of the dye.

b. The concentration of BSP in peripheral venous blood was determined at regular intervals. This concentration, which was shown to equal that in arterial blood, was assumed to be equivalent, for the purpose of estimating hepatic blood flow, to the BSP level in blood reaching the liver.

c. The concentration of BSP in blood leaving the liver was determined at intervals which corresponded as closely as possible with the sampling of peripheral blood. Hepatic venous blood was obtained from a right hepatic vein by a modification of the venous catheterization technique of Cournand(8).

d. Given the rate at which BSP was removed from the blood by the liver, the concentration of BSP in blood afferent to the liver, and the concentration in blood leaving the liver, hepatic blood flow was calculated according to the "Fick principle." Since the BSP concentration was determined in blood leaving a portion of the liver and not in mixed venous blood from the whole liver, the calculated blood flow was designated estimated hepatic blood flow (EHBF).

2. In 23 subjects without gross hepatic disease, the EHBF varied from 1,085 to $1,845 \mathrm{ml}$. per minute per $1.73 \mathrm{M}^{2}{ }^{2}$ of body surface with an average of $1,497 \mathrm{ml}$. No evidence of irregular shunting or gross alternation of blood flow in the human liver was obtained, for the flow appeared to be quite constant under the conditions of our study.

We are indebted to Misses Doris Bullard, Wilma Howe, Elizabeth Nolan, and Constance Qua for technical assistance.

\section{BIBLIOGRAPHY}

1. Burton-Opitz, R., The vascularity of the liver. IV. The magnitude of the portal inflow. Quart. J. Exper. Physiol., 1911, 4, 113.

2. Barcroft, J., and Shore, L. E., The gaseous metabolism of the liver. I. In fasting and late digestion. J. Physiol., 1913, 45, 296.

3. MacLeod, J. J. R., and Pearce, R. G., The outflow of blood from the liver as affected by variations in the condition of the portal vein and hepatic artery. Am. J. Physiol., 1914, 35, 87.

4. Griffith, F. R., Jr., and Emery, F. E., The vasomotor control of the liver circulation. Am. J. Physiol., 1930, 95, 20.

5. Blalock, A., and Mason, M. F., Observations on the blood flow and gaseous metabolism of the liver of unanesthetized dogs. Am. J. Physiol., 1936, 117, 328.

6. Grodins, F. S., Osborne, S. L., Ivy, A. C., and Goldman, L., The effect of bile acids on hepatic blood flow. Am. J. Physiol., 1941, 132, 375.

7. Grindlay, J. H., Herrick, J. F., and Mann, F. C., Measurement of the blood flow of the liver. Am. J. Physiol., 1941, 132, 489.

8. Cournand, A., Riley, R. L., Breed, E. S., Baldwin, E. deF., and Richards, D. W., Jr., Measurement of cardiac output in man using the technic of catheterization of the right auricle or ventricle. J. Clin. Invest., 1945, 24, 106.

9. Gibson, J. G., 2nd, and Evans, W. A., Jr., Clinical studies of the blood volume. II. The relation of plasma and total blood volume to venous pressure, blood velocity rate, physical measurements, age and sex in ninety normal humans. J. Clin. Invest., 1937, $16,317$.

10. Klein, R. I., and Levinson, S. A., Removal of bromsulphalein from the blood stream by the reticuloendothelial system. Proc. Soc. Exper. Biol. and Med., 1933, 31, 179.

11. Mills, M. A., and Dragstedt, C. A., Bromsulphalein dye retention test as a measure of functional activity of reticulo-endothelial system. Proc. Soc. Exper. Biol. and Med., 1936, 34, 228.

12.. Unpublished data.

13. Wakim, K. G., The effect of certain substances on the intrahepatic circulation of blood in the intact animal. Am. Heart J., 1944, 27, 289.

14. Wakim, K. G., and Mann, F. C., The intrahepatic circulation of blood. Anat. Rec., 1942, 82, 233.

15. Olds, J. M., and Stafford, E. S., On the manner of anastomosis of the hepatic and portal circulations. Bull. Johns Hopkins Hosp., 1930, 47, 176. 